\title{
Significant association of XRCC4 single nucleotide polymorphisms with prostate cancer susceptibility in Taiwanese males
}

\author{
CHAO-HSIANG CHANG ${ }^{3,5}$, CHANG-FANG CHIU ${ }^{1,5}$, HSI-CHIN WU ${ }^{3,5}$, HSIEN-CHANG TSENG ${ }^{4,5}$, \\ CHUNG-HSING WANG ${ }^{2,5}$, CHENG-CHIEH LIN ${ }^{5,7}$, CHIA-WEN TSAI ${ }^{5,6}$, SHIU-YUN LIANG ${ }^{5}$, \\ CHENG-LI WANG ${ }^{5^{*}}$ and DA-TIAN BAU ${ }^{5,6^{*}}$ \\ Departments of ${ }^{1}$ Hematology and Oncology, ${ }^{2}$ Pediatrics, ${ }^{3}$ Urology, ${ }^{4}$ Otolaryngology, and the ${ }^{5}$ Terry Fox Cancer \\ Research Laboratory, China Medical University Hospital; ${ }^{6}$ Graduate Institute of Chinese Medical Science, \\ China Medical University; ${ }^{7}$ College of Health Science, Asia University, Taichung, Taiwan, R.O.C.
}

Received January 14, 2008; Accepted March 21, 2008

\begin{abstract}
The DNA repair gene X-ray cross-complementing group 4 (XRCC4), a member of the non-homologous endjoining (NHEJ) repair system, plays a major role in the repair of the double-strand breaks of the DNA sequence. This gene is critical to the maintenance of overall genome stability, and is also thought to play a key role in human carcinogenesis. In this case-control study, several novel polymorphic variants of XRCC4, including C-1622T (rs7727691), G-1394T (rs6869366), C-571T (rs2075686) and intron3 DIP (rs28360071), were investigated, and the correlation of these variants to prostate cancer susceptibility in a Taiwanese population was observed. A total of 134 prostate cancer patients were recruited along with 134 age-matched healthy controls, and the association of their selected genotypes with susceptibility to prostate cancer was determined. The G-1394T variant of XRCC4 proved, after analysis of the frequencies of each variant in the prostate cancer and control groups, to be a significant single nucleotide polymorphism (SNP) in prostate carcinogenesis. Our data clearly indicate that the heterogeneous $\mathrm{G}$ of G-1394T increases the risk of suceptibility to prostate cancer $(\mathrm{P}=0.0106)$, while no difference in distribution of XRCC4 C-1622T (rs7727691), C-571T (rs2075686) or intron3 DIP (rs28360071) between the prostate cancer and control groups was found. In conclusion, our findings suggest that the $\mathrm{G}$ allele of XRCC4 G-1394T may be responsible for prostate carcinogenesis, and could be useful in the early detection and prevention of the disease.
\end{abstract}

Correspondence to: Dr Da-Tian Bau, Terry Fox Cancer Research Laboratory, China Medical University Hospital, 2 Yuh-Der Road, Taichung 404, Taiwan, R.O.C.

E-mail: datian@mail.cmuh.org.tw

${ }^{*}$ Contributed equally

Key words: XRCC4, single nucleotide polymorphism, prostate, DNA repair

\section{Introduction}

Prostate cancer is one of the most serious diseases affecting males worldwide, though its incidence varies widely according to race. In America and Western Europe, it is a leading cause of illness and death in males (1) while, according to the literature, Asians have the lowest incidence and AfricanAmericans the highest incidence in the world (2). In Taiwan, although the occurence of prostate cancer is much lower than in other countries, the disease nonetheless ranks seventh of the ten most common causes of cancer-related death in men (3). The number of prostate cancer patients and the death rate associated with the disease have increased over the past two decades (3), and it has become a serious threat to mature Taiwanese males. Several risk factors associated with prostate cancer have been confirmed in the literature, including age, race and a family history of prostate cancer (2). Diet, androgens, occupational chemicals, smoking, inflammation and obesity are considered to be additional secondary risk factors (2).

The detection of single nucleotide polymorphisms (SNPs) has become a convenient and powerful tool in cancer research, especially for the determination of new genetic risk factors. Previous research has proven that several SNPs are associated with prostate cancer (4). These genetic polymorphisms, especially those located on the DNA repair system genes, can be considered potential risk factors for the disease. The DNA repair system is one of the most delicate and important defenses against cancer, and deficient function of this system has been reported to lead to many lethal diseases, including various cancers (4-9). The genes of the DNA repair system are therefore reasonable candidates for the identification of novel biomarkers in prostate cancer.

Many genes play important roles in the repair pathway, such as the X-ray cross-complementing group 4 (XRCC4) gene. $X R C C 4$ is an important member of the non-homologous end-joining (NHEJ) repair system, not only working in conjunction with $\mathrm{Ku} 70 / \mathrm{Ku} 80$ and ligase 4, but also playing a major role in the precision end joining of blunt DNA doublestrand breaks $(10,11)$. Several known SNPs on the XRCC4 gene have been reported to be associated with gastric, oral and breast cancer $(5,9,12)$, indicating that they might play 
common and central roles in various cancers, including that of the prostate. Other studies have shown that the inactivation of the XRCC4 gene in a mouse model can cause the loss of the normal function of differentiation in lymphocytes and neurons, leading to various embryonic lethal injuries $(13,14)$. These findings suggest that mutations of the XRCC4 gene induce serious syndromes from a very early age. As prostate cancer most commonly affects elderly men, these mutations are probably unsuitable targets for prostate cancer biomarkers. We therefore focused our research on the SNPs of XRCC4, hypothesizing that, though variant genotypes of SNPs may not cause lethal injuries in younger males, they might slightly increase the possibility of genomic instability and lead to prostate carcinogenesis with increasing age.

The aim of this study was to identify several useful biomarkers of prostate cancer in Taiwanese men in order to attenuate this public threat. To the best of our knowledge, it is the first study to investigate the role of $\mathrm{XRCC4}$ in prostate cancer. Four SNPs on XRCC4 were selected, the genotypes of prostate cancer patients and non-cancer controls identified and the distribution of frequencies in both groups compared, then the association between $\mathrm{XRCC} 4$ and the risk of prostate cancer was analyzed.

\section{Materials and methods}

Study population and sample collection. A total of 134 male patients diagnosed with prostate cancer were recruited at the general surgery outpatient clinics of the China Medical University Hospital (Taichung, Taiwan, R.O.C.) between 2003 and 2007. An equal number of non-prostate cancer healthy males were selected as controls and age matched after initial random sampling from the Health Examination Cohort of the hospital. The mean age of the prostate cancer patients was 71.7 $(\mathrm{SD}=6.4)$ and of the controls $71.5(\mathrm{SD}=6.6)$ years. All patients voluntarily participated, completed a self-administered questionnaire and provided peripheral blood samples. Clinical characteristics were defined by two expert surgeons, Drs Chang and $\mathrm{Wu}$. The control subjects had no significant voiding symptoms (American Urological Association symptom score <8) (15), prostate-specific antigen levels within the normal limit $(<4 \mathrm{ng} / \mathrm{ml})$, no history of prostate surgery and no clinical signs of prostate hyperplasia or prostate cancer during digital rectal examination. Those with other known malignancies or a history of cancer were excluded. Subjects who smoked more than 10 cigarettes per week for at least 6 months were defined as smokers, those who had regularly chewed areca for at least 6 months were defined as areca quid chewers, and those who had consumed beer, wine or distilled spirits more than twice a week for at least 6 months were defined as alcoholic beverage drinkers. Based on the criteria outlined by the American Joint Committee on Cancer Tumor-Node-Metastasis classification system (American Joint Committee on Cancer Staging Manual, 5th edition, 1997), disease stage was determined according to pathologic findings, pelvic computed tomography or magnetic resonance imaging and radionucleotide bone scans. Pathologic grade was determined according to the Gleason score (16) and classified into three groups: well-differentiated (Gleason score 2-4), moderately-differentiated (Gleason score 5-6) and poorly-differentiated (Gleason score 7-10). The study was approved by the Institutional Review Board of the China
Medical University Hospital, and written informed consent was obtained from all participants.

Genotyping assays. Genomic DNA was prepared from peripheral blood leukocytes using a QIAamp Blood Mini Kit (Blossom, Taipei, Taiwan) and further processed as previously described $(4-9,17,18)$. The following primers were used: for XRCC4 C-1622T rs7727691, 5'-AAGATACTGAGACACTA ATC-3' and 5'-CACAACATAACTAAGGATGA-3'; for XRCC4 G-1394T rs6869366, 5'-GATGCGAACTCAAAGA TACTGA-3' and 5'-TGTAAAGCCAGTACTCAAACTT-3'; for XRCC4 C-571T rs2075686, 5'-GGCTACTGACTAAAC AGATG-3' and 5'-TAACACGTTGGCTACGTAGA-3'; and for XRCC4 intron3 DIP rs28360071, 5'-TCCTGTTACCATT TCAGTGTTAT-3' and 5'-CACCTGTGTTCAATTCCAG CTT-3'. The following cycling conditions were performed: one cycle at $94^{\circ} \mathrm{C}$ for $5 \mathrm{~min} ; 35$ cycles at $94^{\circ} \mathrm{C}$ for $30 \mathrm{sec}, 55^{\circ} \mathrm{C}$ for $30 \mathrm{sec}$ and $72^{\circ} \mathrm{C}$ for $30 \mathrm{sec}$; and a final extension at $72^{\circ} \mathrm{C}$ for $10 \mathrm{~min}$. The PCR products of XRCC4 C-1622T rs7727691 (cut from 218 bp T type into $32+186$ bp C type), G-1394T rs6869366 (cut from 300 bp T type into $200+100$ bp $\mathrm{G}$ type) and C-571T rs2075686 (cut from 197 bp C type into 69+128 bp T type) were studied after digestion with the Fnu4HI, Hinc II and $M n l I$ restriction enzymes, respectively.

Statistical analysis. Only those matches for which all DNA polymorphism data was available (case/control $n=134 / 134$ ) were selected for final analysis. To ensure that the controls used were representative of the general population and to exclude the possibility of genotyping error, the deviation of the genotype frequencies of XRCC4 SNPs in the control subjects from Hardy-Weinberg equilibrium was assessed by the goodness-of-fit test. Pearson's $\chi^{2}$ test or Fisher's exact test (when the expected number in any cell was $<5$ ) were used to compare the distribution of XRCC4 genotypes between the cases and controls. $\mathrm{P}<0.05$ was considered statistically significant.

\section{Results}

The clinical characteristics of the 134 prostate cancer patients and 134 age-matched controls are shown in Table I. The frequency of the genotypes for the XRCC4 promoters -1622 , $-1394,-571$ and of intron3 DIP in the prostate cancer and control groups is shown in Table II. The genotype distribution of various SNPs of the XRCC4 promoter -1394 differed significantly between the prostate cancer and control groups $(\mathrm{P}<0.05)$, while that of the promoters $-1622,-571$ and of intron3 DIP did not ( $\mathrm{P}>0.05$; Table II). In detail, the distribution of the XRCC4 promoters in the prostate cancer and control groups were as follows: $-1622 * \mathrm{C}$ homozygote/heterozygote/T homozygote, 85.1/14.9/0\% and 87.3/12.7/0\%, respectively $(\mathrm{P}=0.5952$; Table $\mathrm{II}) ;-1394 * \mathrm{G}$ homozygote/ heterozygote/T homozygote, $0 / 15.7 / 84.3 \%$ and $0 / 6.0 / 94.0 \%$, respectively $(\mathrm{P}=0.0105$; Table $\mathrm{II}) ;-571 * \mathrm{C}$ homozygote/ heterozygote/T homozygote, 55.2/36.6/8.2\% and 58.2/35.1/ $6.7 \%$, respectively ( $\mathrm{P}=0.8407$; Table II); and of intron3 DIP *insertion homozygote/heterozygote/deletion homozygote, $66.4 / 26.9 / 6.7 \%$ and $69.4 / 24.6 / 6.0 \%$, respectively $(\mathrm{P}=0.8705$; Table II). To sum up, the XRCC4 promoter -1394 heterozygote is associated with a higher susceptibility to prostate cancer. 
Table I. Clinical characteristics of the prostate cancer patients and healthy controls.

\begin{tabular}{|c|c|c|c|c|c|}
\hline \multirow[b]{2}{*}{ Characteristics } & \multicolumn{2}{|c|}{ Patients $(n=134)$} & \multicolumn{2}{|c|}{ Controls $(n=134)$} & \multirow[b]{2}{*}{ P-value } \\
\hline & No. $(\%)$ & Mean (SD) & No. $(\%)$ & Mean (SD) & \\
\hline Age (years) & & $71.5(6.6)$ & & $71.7(6.4)$ & 0.89 \\
\hline Body mass index $\left(\mathrm{kg} / \mathrm{m}^{2}\right)$ & & $24.2(4.2)$ & & $23.9(3.1)$ & 0.91 \\
\hline Prostate volume (ml) & & $36.7(23.1)$ & & $<20$ & $<0.01$ \\
\hline Prostate-specific antigen level $(\mathrm{ng} / \mathrm{ml})$ & & $34.7(36.3)$ & & $1.2(0.8)$ & $<0.01$ \\
\hline Cigarette smokers & $71(52.9)$ & & $76(56.7)$ & & 0.54 \\
\hline Alcohol drinkers & $64(47.7)$ & & $60(44.8)$ & & 0.62 \\
\hline Areca chewers & $15(11.2)$ & & $13(9.7)$ & & 0.69 \\
\hline \multicolumn{6}{|l|}{ Disease stage } \\
\hline Localized & $67(50.0)$ & & & & \\
\hline Locally advanced & $39(29.1)$ & & & & \\
\hline Bone metastasis & $21(15.7)$ & & & & \\
\hline Not assessed & $7 \quad(5.2)$ & & & & \\
\hline \multicolumn{6}{|l|}{ Pathologic grade } \\
\hline Well-differentiated & $17(12.7)$ & & & & \\
\hline Moderately-differentiated & $55(41.0)$ & & & & \\
\hline Poorly-differentiated & $62(46.3)$ & & & & \\
\hline
\end{tabular}

Table II. Frequency of the genotypes of the XRCC4 C-1622T (rs7727691), G-1394T (rs6869366), C-571T (rs2075686) and intron3 DIP (rs28360071) polymorphisms in the prostate cancer patients and healthy controls.

\begin{tabular}{|c|c|c|c|c|c|}
\hline Genotype & Controls & $\%$ & Patients & $\%$ & P-value ${ }^{a}$ \\
\hline \multicolumn{6}{|c|}{ C-1622T rs7727691 } \\
\hline $\mathrm{CC}$ & 117 & 87.3 & 114 & 85.1 & 0.595260 \\
\hline $\mathrm{CT}$ & 17 & 12.7 & 20 & 14.9 & \\
\hline TT & 0 & 0.0 & 0 & 0.0 & \\
\hline \multicolumn{6}{|c|}{ G-1394T rs6869366 } \\
\hline GG & 0 & 0.0 & 0 & 0.0 & 0.010579 \\
\hline GT & 8 & 6.0 & 21 & 15.7 & \\
\hline TT & 126 & 94.0 & 113 & 84.3 & \\
\hline \multicolumn{6}{|c|}{ C-571T rs2075686 } \\
\hline $\mathrm{CC}$ & 78 & 58.2 & 74 & 55.2 & 0.840747 \\
\hline $\mathrm{CT}$ & 47 & 35.1 & 49 & 36.6 & \\
\hline TT & 9 & 6.7 & 11 & 8.2 & \\
\hline \multicolumn{6}{|c|}{ Intron3 DIP rs28360071 } \\
\hline II & 93 & 69.4 & 89 & 66.4 & 0.870589 \\
\hline ID & 33 & 24.6 & 36 & 26.9 & \\
\hline DD & 8 & 6.0 & 9 & 6.7 & \\
\hline
\end{tabular}

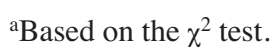




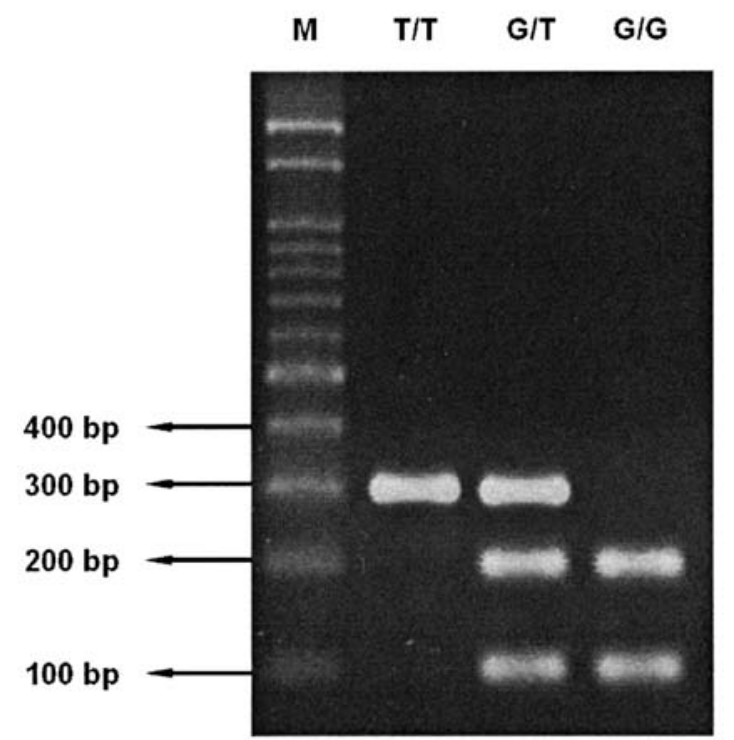

Figure 1. PCR-based restriction analysis of the G-1394T polymorphism of the XRCC4 gene by 3\% agarose gel electrophoresis. M, 100-bp DNA size marker; $\mathrm{T} / \mathrm{T}$, indivisible homozygote; G/T, heterozygote; G/G, divisible homozygote.

The representative PCR-based restriction analyses for the XRCC4 promoter -1394 polymorphisms are shown in Fig. 1.

The frequency of the alleles of the XRCC4 promoters $-1622,-1394,-571$ and of intron3 DIP in the prostate cancer and control groups is shown in Table III. The distribution of all these polymorphisms was in Hardy-Weinberg equilibrium and was similar in the prostate cancer patients and the controls (data not shown). Allele frequency distributions of the XRCC4 promoter $-1394 * \mathrm{G}$ is associated with a higher susceptibility to prostate cancer. In detail, the distribution of the XRCC4 promoters in the prostate cancer and control groups was as follows: $-1622 \mathrm{C} / \mathrm{T}$ allele, $92.5 / 7.5$ and $93.7 / 6.3 \%(\mathrm{P}=0.6092)$;
$-1394 \mathrm{G} / \mathrm{T}$ allele, 7.8/92.2 and 3.0/97.0\% ( $\mathrm{P}=0.01306) ;-571$ G/T allele, 73.5/26.5 and 75.7/24.3\% ( $\mathrm{P}=0.5514)$; and of the intron3 DIP insertion/deletion allele, 79.9/20.1 and 81.7/18.3\%, respectively ( $\mathrm{P}=0.5835$; Table III).

\section{Discussion}

To the best of our knowledge, there has been no study investigating the correlation between $\mathrm{XRCC4}$, a gene which plays a major role in the NHEJ DNA double-strand break repair pathway, and prostate cancer. Based on our results, the -1394 polymorphism on the XRCC4 gene is indeed associated with prostate carcinogenesis. It can be hypothesized that this variant polymorphism alters the normal expression and function of $X R C C 4$ by lowering its expression or by exchanging the major amino acid of its protein products. While these changes may initially be very subtle and cause no obvious pathological changes in the human body, they may eventually lead to lowered capacities of the NHEJ or other DNA repair pathways in which the XRCC4 gene is involved. As individuals age or are exposed to more carcinogens, genomic instabilities becomes more likely, and the need for an intracellular repair system to stem these injuries increases as well. In individuals whose DNA repair system does not perform with normal efficiency, it is possible that DNA adducts will fail to be removed thoroughly and in a timely fashion. Offspring who inherit these genetic deficiencies will have an increased number of abnormal cells, raising the risk of carcinogenesis.

The results of this case-control study have provided evidence supporting our initial hypothesis. We found that the -1394 SNP was significantly associated with prostate cancer in Taiwanese males. This SNP is therefore a potential biomarker for the prevention of prostate carcinogenesis. Although it was previously known that the XRCC4 gene plays an important role in the DNA repair pathway and in carcino-

Table III. Allele frequencies of the XRCC4 C-1622T (rs7727691), G-1394T (rs6869366), C-571T (rs2075686) and intron3 DIP (rs28360071) polymorphisms in the prostate cancer patients and controls.

\begin{tabular}{|c|c|c|c|}
\hline Allele & $\begin{array}{c}\text { Controls }(\%) \\
n=268\end{array}$ & $\begin{array}{c}\text { Patients }(\%) \\
n=268\end{array}$ & P-value ${ }^{a}$ \\
\hline \multicolumn{4}{|c|}{ C-1622T rs7727691 } \\
\hline Allele C & $251(93.7)$ & $248(92.5)$ & 0.60924 \\
\hline Allele T & $17(6.3)$ & $20 \quad(7.5)$ & \\
\hline \multicolumn{4}{|c|}{ G-1394T rs6869366 } \\
\hline Allele G & $8 \quad(3.0)$ & $21 \quad(7.8)$ & 0.01306 \\
\hline Allele T & $260(97.0)$ & 247 (92.2) & \\
\hline \multicolumn{4}{|c|}{ C-571T rs2075686 } \\
\hline Allele C & $203(75.7)$ & $197(73.5)$ & 0.55146 \\
\hline Allele T & $65(24.3)$ & $71(26.5)$ & \\
\hline \multicolumn{4}{|c|}{ Intron3 DIP rs28360071 } \\
\hline Insertion & $219(81.7)$ & $214(79.9)$ & 0.58359 \\
\hline Deletion & $49(18.3)$ & $54(20.1)$ & \\
\hline
\end{tabular}

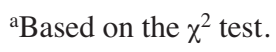


genesis, the details of this pathway and of several promoter assays in patient cells have been further confirmed.

The -1394 SNP is located at 1394 bp upstream of the $X R C C 4$ gene, and is responsible for regulating gene expression. It is commonly thought that variations of the sequence of the promoter region are associated with a different level of gene expression. Thus, this type of polymorphism may influence the expression level of the gene. It is possible that the variants of these specific SNPs cause an abnormal capacity for protein products, leading to various deficiencies. When a DNA repair gene is incapable of normal expression, its downstream genes are directly affected, causing the malfunction of the entire pathway. Thus, these variants lead to a lowered capacity of the repair system and increase the possibility of cancer and other cell pathogeneses.

In this study, we found that the $\mathrm{G}$ allele of $\mathrm{G}-1394 \mathrm{~T}$ in $X R C C 4$ is a risk factor for prostate cancer, as the number of individuals who were GT heterozygous was higher in the patient than in the control group. Though we did not find any GG homologues in the patients or the controls, it is possible that the $G$ allele dramatically weakens the efficiency of the promoter. That is to say, though one $\mathrm{G}$ allele may influence the functioning of the DNA repair pathway only slightly as the remaining $\mathrm{T}$ allele can maintain normal levels of most of its functions and other NHEJ genes can undertake the process normally, in individuals who are GG homologous, cells may have a lowered capacity for DNA repair, and may thus end up causing severe and lethal deficiencies. This genetic variant is a risk factor at a very early age, which in part explains why we did not find the GG homologous state in either our case or control groups.

Using the TT allele subgroup as a reference, the risk of prostate cancer is more than twice as high in the GT allele subgroup. This result additionally confirms our hypothesis. The $X R C C 4$ gene plays a central role in the NHEJ repair system, and is very important to the maintainance of genomic stability. It is therefore possible that individuals with the GT genotype of this XRCC4 SNP have lowered NHEJ capacity compared to those with the TT genotype, resulting in deficient removal of double-strand breaks in their genome. This suggests the nature of the relationship between $X R C C 4$ and prostate cancer. It is known that double-strand breaks are one of the most severe types of DNA damage; when this type of damage is not repaired before the duplication of the genome, it causes irreversible cellular injury, increasing the possibility of prostate carcinogenesis.

In addition to our study on prostate cancer, there have been several studies showing that variations of the XRCC4 gene are associated with many other cancers $(5,9,12)$. Therefore, $X R C C 4$ and the DNA double-strand break repair pathway may serve as a common mechanism of early carcinogenesis. It is clear that the phenotypes, such as DNA double-strand break repair capacity and the correlation between genotype and phenotype, need to be further investigated.

In this study, we screened four SNPs of the XRCC4 gene and investigated the association of their genotypes with prostate cancer susceptibility. The -1622 and -571 SNPs, though located in the promoter region along with G-1394T, did not seem to be associated with an increased risk of prostate cancer, but are perhaps not as critical as the G-1394T variant to the regulation of $X R C C 4$ gene expression. The promoter of the $X R C C 4$ gene is in need of further study, by means such as promoter assays, to reveal the role of each section or even of each nucleotide in the subtle regulation of the transcriptional, translational and post-translational expression of the XRCC4 gene. Such investigation may prove to demonstrate that the -1622 and -571 SNPs, along with other SNPs in the promoter region, play a role in prostate cancer progression through their joint effects. Certainly, larger population size and genomicenvironmental combination studies could provide more comprehensive and realistic progress in prostate oncology. In summary, the -1394 of the XRCC4 gene could serve as a biomarker of prostate cancer and should be a target of cancer prevention and anticancer therapy.

\section{Acknowledgements}

We thank Yung-Shun Kuo, Po-Chi Hsu and Chiao-Lin Lin for their technical assistance. This study was supported by research grants from the China Medical University and Hospital (DMR-97-063) and the National Science Council (NSC 952320-B-039-014-MY3).

\section{References}

1. Gronberg H: Prostate cancer epidemiology. Lancet 361: 859-864, 2003.

2. Hsing AW and Chokkalingam AP: Prostate cancer epidemiology. Front Biosci 11: 1388-1413, 2006.

3. Department of Health, Taiwan: Cancer registration system annual report. Department of Health, Taiwan, 2006.

4. Bau DT, Wu HC, Chiu CF, Lin CC, Hsu CM, Wang CL, Wang RF and Tsai FJ: Association of XPD polymorphisms with prostate cancer in Taiwanese patients. Anticancer Res 27: 2893-2896, 2007.

5. Chiu CF, Wang CH, Wang CL, Lin CC, Hsu NY, Weng JR and Bau DT: A novel single nucleotide polymorphism in XRCC4 gene is associated with gastric cancer susceptibility in Taiwan. Ann Surg Oncol 15: 514-518, 2008.

6. Chiu CF, Tsai MH, Tseng HC, Wang CL, Tsai FJ, Lin CC and Bau DT: A novel single nucleotide polymorphism in ERCC6 gene is associated with oral cancer susceptibility in Taiwanese patients. Oral Oncol (In press).

7. Bau DT, Tsai MH, Lo YL, Hsu CM, Tsai Y, Lee CC and Tsai FJ: Association of p53 and p21(CDKN1A/WAF1/CIP1) polymorphisms with oral cancer in Taiwan patients. Anticancer Res 27: 1559-1564, 2007.

8. Bau DT, Mau YC, Ding SL, Wu PE and Shen CY: DNA doublestrand break repair capacity and risk of breast cancer. Carcinogenesis 28: 1726-1730, 2007.

9. Chiu CF, Tsai MH, Tseng HC, Wang CL, Wang CH, Wu CN, Lin CC and Bau DT: A novel single nucleotide polymorphism in XRCC4 gene is associated with oral cancer susceptibility in Taiwanese patients. Oral Oncol (In press).

10. Mari PO, Florea BI, Persengiev SP, Verkaik NS, Bruggenwirth HT, Modesti M, Giglia-Mari G, Bezstarosti K, Demmers JA, Luider TM, Houtsmuller AB and van Gent DC: Dynamic assembly of end-joining complexes requires interaction between Ku70/80 and XRCC4. Proc Natl Acad Sci USA 103: 18597-18602, 2006

11. Van Heemst D, Brugmans L, Verkaik NS and van Gent DC: End-joining of blunt DNA double-strand breaks in mammalian fibroblasts is precise and requires DNA-PK and XRCC4. DNA Repair 3: 43-50, 2004.

12. Fu YP, Yu JC, Cheng TC, Lou MA, Hsu GC, Wu CY, Chen ST, Wu HS, Wu PE and Shen CY: Breast cancer risk associated with genotypic polymorphism of the nonhomologous end-joining genes: a multigenic study on cancer susceptibility. Cancer Res 63: 2440-2446, 2003.

13. Gao Y, Ferguson DO, Xie W, Manis JP, Sekiguchi J, Frank KM, Chaudhuri J, Horner J, De Pinho RA and Alt FW: Interplay of p53 and DNA-repair protein XRCC4 in tumorigenesis, genomic stability and development. Nature 404: 897-900, 2000. 
14. Gao Y, Sun Y, Frank KM, Dikkes P, Fujiwara Y, Seidl KJ, Sekiguchi JM, Rathbun GA, Swat W, Wang J, Bronson RT, Malynn BA, Bryans M, Zhu C, Chaudhuri J, Davidson L, Ferrini R, Stamato T, Orkin SH, Greenberg ME and Alt FW: A critical role for DNA end-joining proteins in both lymphogenesis and neurogenesis. Cell 95: 891-902, 1998.

15. Barry MJ, Fowler FJ Jr, O'Leary MP, Bruskewitz RC, Holtgrewe HL, Mebust WK and Cockett AT: The American Urological Association symptom index for benign prostatic hyperplasia. The Measurement Committee of the American Urological Association. J Urol 148: 1549-1557, 1992.
16. Gleason DF and Mellinger GT: Prediction of prognosis for prostatic adenocarcinoma by combined histological grading and clinical staging. J Urol 111: 58-64, 1974.

17. Matlashewski GJ, Tuck S, Pim D, Lamb P, Schneider J and Crawford LV: Primary structure polymorphism at amino acid residue 72 of human p53. Mol Cell Biol 7: 961-963, 1987.

18. Thomas M, Kalita A, Labrecque S, Pim D, Banks L and Matlashewski G: Two polymorphic variants of wild-type p53 differ biochemically and biologically. Mol Cell Biol 19: 1092-1100, 1999. 